\title{
Pectus carinatum: When less is more
}

\author{
M Martinez-Ferro, ${ }^{1} \mathrm{MD}$; G Bellia-Munzon, ${ }^{1} \mathrm{MD}$; I A Schewitz, ${ }^{2} \mathrm{MB}$ ChB, FCS (Cardiothoracic Surg); L Toselli, ${ }^{1} \mathrm{MD}$
}

${ }^{1}$ Fundación Hospitalaria Mother and Child Medical Centre, Buenos Aires, Argentina

${ }^{2}$ Department of Cardiothoracic Surgery, School of Medicine, Faculty of Health Sciences, University of Pretoria, South Africa

Corresponding author: M Martinez-Ferro (m.martinezferro@gmail.com)

\begin{abstract}
Awareness of pectus carinatum has increased among the medical community over the last several decades, as innovative options for nonsurgical treatments have become more widely known. Management alternatives have shifted from open resective to minimally invasive strategies, and finally, to reshaping the chest using both surgical and non-surgical modalities. We aim to review the evolution of the diagnosis and treatment of pectus carinatum up to its current management.
\end{abstract}

Afr J Thoracic Crit Care Med 2019;25(3):116-122. https://doi.org/10.7196/AJTCCM.2019.v25i3.019

Although pectus carinatum has classically been seen as an isolated protrusion of the sternum, the condition comprises a deformity of the entire thoracic cage, both the sternum and the adjacent chondrocostal structures (Fig. 1). Aside from the negative aesthetic impact, patients with pectus carinatum have psychological problems, impairments in their social interactions, spinal misalignments, poor posture and back pain. While infrequent, cardiopulmonary associations have been described, ${ }^{[1]}$ and it is associated with syndromes such as Noonan, Marfan and von Recklinghausen, which also have a pectus deformity. ${ }^{[2,3]}$ In 1958, Currarino and Silverman ${ }^{[4]}$ described a special type of carinatum, pectus arcuatum, in association with cardiovascular anomalies. Several important developments in the diagnosis and treatment of pectus carinatum have taken place since these initial steps. Our aim is to describe these events in a way that enables paediatric and general thoracic surgeons to understand the origins and evolution of this disease and its treatment.

A Medline literature search was undertaken using the MeSH term 'pectus carinatum'. A total of 382 articles were retrieved. A subset was chosen according to the authors' view of the best description of the evolution of diagnosis and treatment of pectus carinatum.

\section{Incidence, aetiology and classification}

The incidence of pectus carinatum is very difficult to estimate because the condition is often underdiagnosed. The development and spread of non-invasive treatment methods

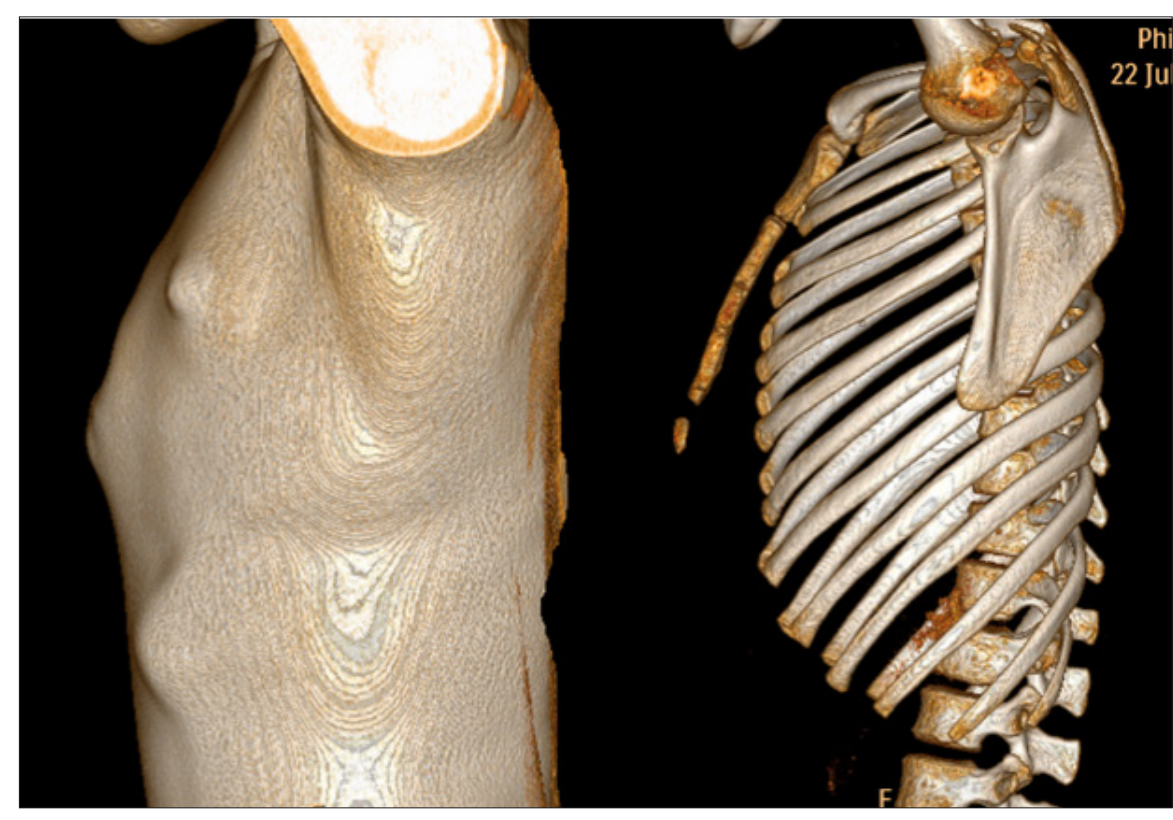

Fig. 1. Chest computed tomography scan with $3 D$ reconstruction of patient with pectus carinatum. This usually comprises the whole thoracic cage, including sternum and chondrocostal structures.

has raised interest in this malformation, and referral has increased exponentially in the last 20 years.

Pectus carinatum is considered the second-most common cause of thoracic malformations. Its reported incidence ranges from a fifth of that of pectus in some centres, to an equal incidence in others. ${ }^{[5,6]}$ It is more prevalent in males, at a ratio of 3 or 4 to $1 .^{[5,6]}$

Aetiology may be primary or secondary. Primary malformations are those with no predisposing factors except for familial aggregation of $25 \%,{ }^{[7]}$ and secondary are those malformations that occur after large sternotomies for cardiac surgeries, or resective operations for pectus excavatum repair. ${ }^{[8,9]}$
Pectus carinatum may be classified as of either chondrogladiolar or chondromanubrial type, depending on the site of the sternal angulation (Fig. 2). In the chondrogladiolar type, the more common one, the acute angle of the sternum is located at the body of the sternum, while in the chondromanubrial type the angle is located cephalad, at the manubrium. The malformation may be also classified according to symmetry: symmetric; asymmetric with sternal rotation to the left or right; and mixed excavatum/carinatum.

Special malformations include pectus arcuatum (Fig. 3), which consists of a short, thick and wide non-segmented sternum with marked posterior angulation at the site 


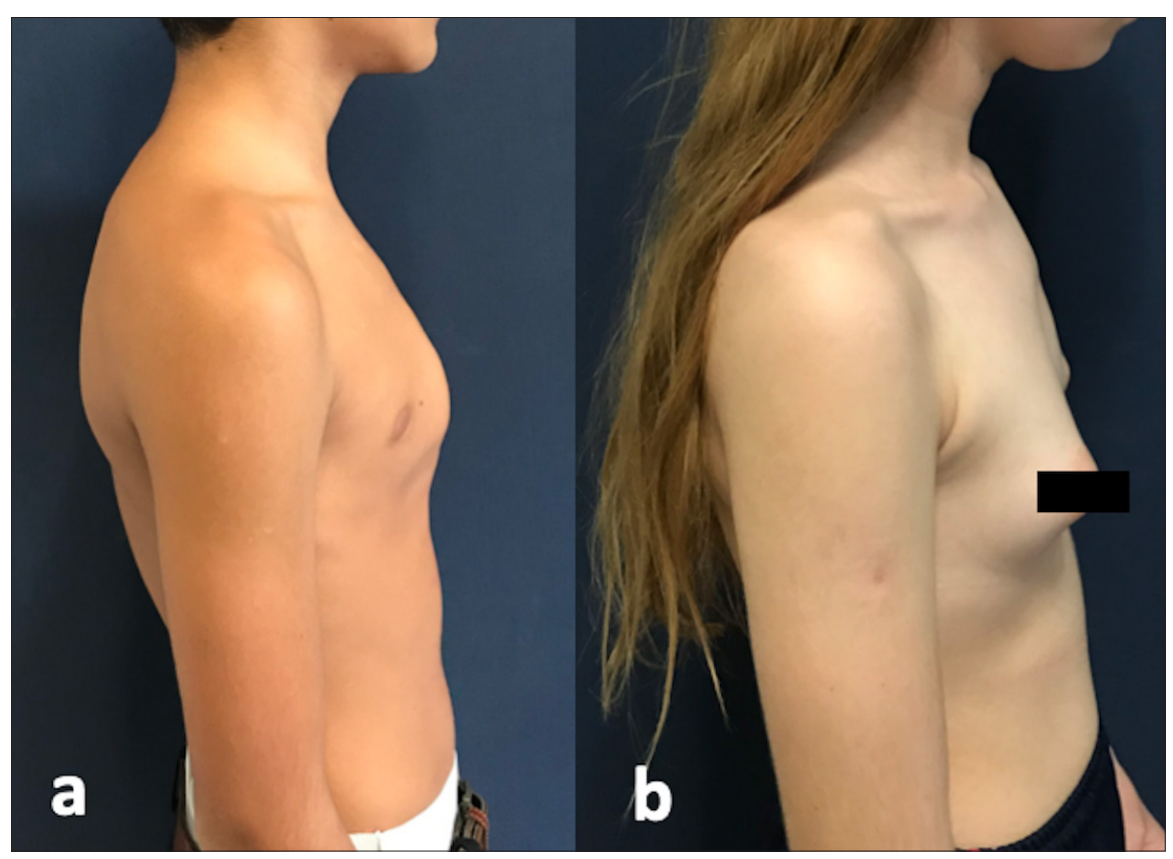

Fig. 2. Types of pectus carinatum: (a) chondrogladiolar and (b) chondromanubrial.

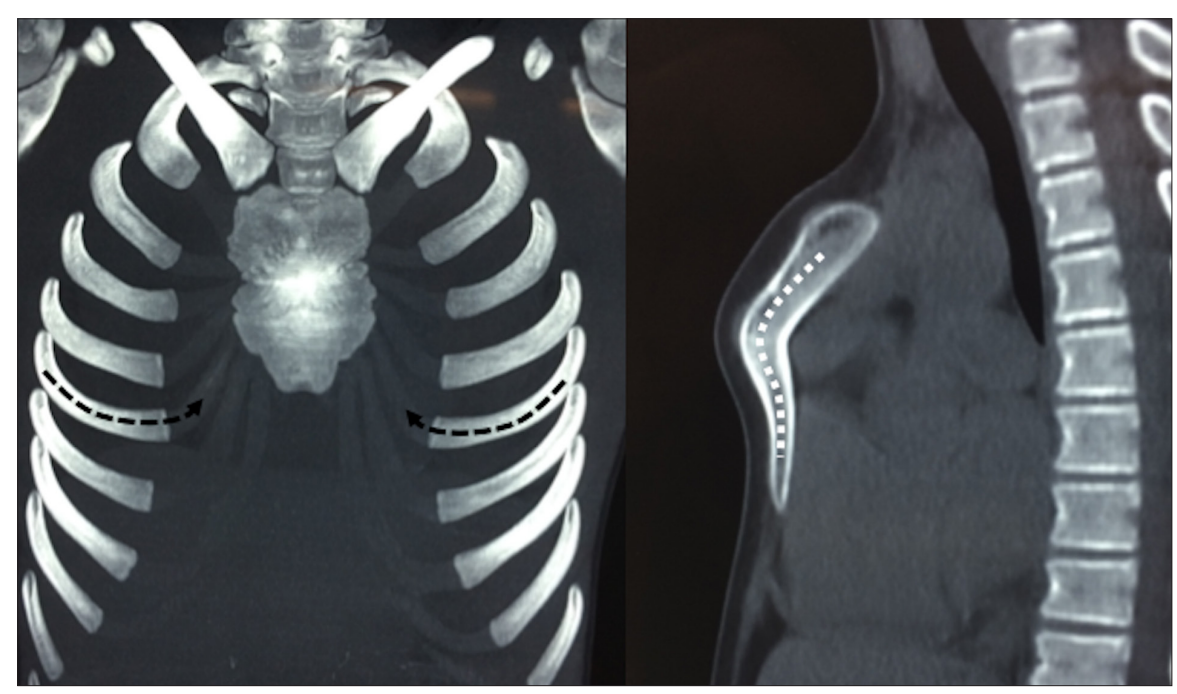

Fig. 3. 3D chest wall computed tomography scan of a patient with pectus arcuatum. This condition causes extensive deformity of adjacent chondrocostal structures. Note the deformed costal arches pointing upwards in order to connect with the shortened sternum (left; black dotted lines). This characteristic short, wide and non-segmented sternum is usually severely bent (right; white dotted lines).

of the normal chondromanubrial junction. When associated with cardiac anomalies, this is referred to as Currarino-Silverman syndrome. ${ }^{[4]}$

Diagnosis is made by physical examination; the deformity can be characterised without complementary studies such as X-ray or computed tomography, which can add no information and in addition require radiation. Systematic photography is used to assess the shape of the chest for the duration of the follow-up period. The elasticity of the sternum and cartilages should always be assessed; this can be achieved subjectively by manual compression or by means of pressuremeasuring devices.

Only in special cases should further studies be done, such as in associated skeletal deformities, or when associated syndromes such as von Recklinghausen, Poland or Marfan, or cardiac conditions, are suspected.

Recently, the use of 3D scanners has been reported for the diagnosis, characterisation and follow-up of patients with pectus carinatum and those with excavatum (Fig. 4). ${ }^{[10,11]}$ Three-dimensional virtual reconstruction allows the attending physicians to measure the severity, the symmetry and the evolution of the deformity with treatment, both operative and non-operative, at outpatient clinics. This technology seems promising and avoids radiation, but it still requires validation.

\section{Treatment}

As is the case for other thoracic deformities, treatment in the modern era began in the mid-20th century, with the first report of an attempt at surgical correction by Ravitch in 1952. ${ }^{[12]}$ Since then, surgeons have reported several different variations on the original technique. Following Nuss et al.'s ${ }^{[13]}$ report of a new non-resective operation for chest remodelling with a high level of success, many surgeons began exploring and publishing their experiences with non-resective surgeries, which included bar implants for pectus both excavatum and carinatum, both intraand extrathoracic.

Although dynamic chest compression was described by Haje and Raymundo ${ }^{[14]}$ as early as 1979 , this modality did not gain popularity among surgeons until the Nuss technique of chest remodelling (instead of resecting) completely changed the conception of treatment.

This change of paradigm inspired surgeons to explore the concept of reshaping the thorax from the outside, avoiding the need for an operation. In 2008, Martinez-Ferro et al. ${ }^{[6]}$ reported the creation of a pressure-controlled bracing system, and described its application in patients, introducing new concepts such as pressure of initial correction and pressure of treatment, as well as the use of pounds per square inch (psi) as a unit of measure for rigidity of the thoracic cage.

In summary, the treatment modalities of pectus carinatum may be either surgical or non-surgical, and surgical treatments are either resective or non-resective (Fig. 5).

\section{Surgical treatments}

Open resective surgeries of the affected cartilages associated with sternal osteotomies were the first operations performed for this thoracic deformity. They consist of large incisions on the chest that are usually submitted to considerable strain, with potential keloid formation, and 


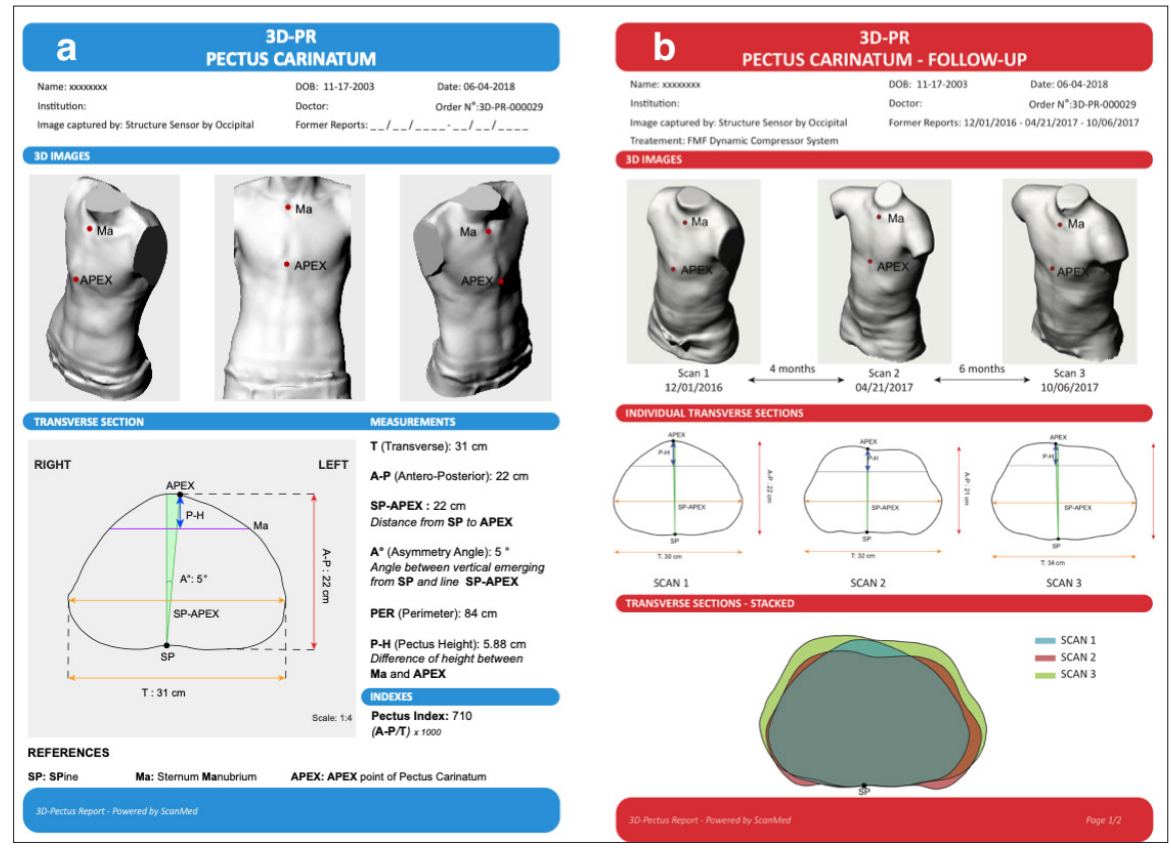

Fig. 4. 3D scanning technology provides high-quality images that are processed to obtain external chest wall indexes. This resource is particularly useful for (a) the evaluation of severity and (b) reporting comparative results, especially during non-surgical treatments.
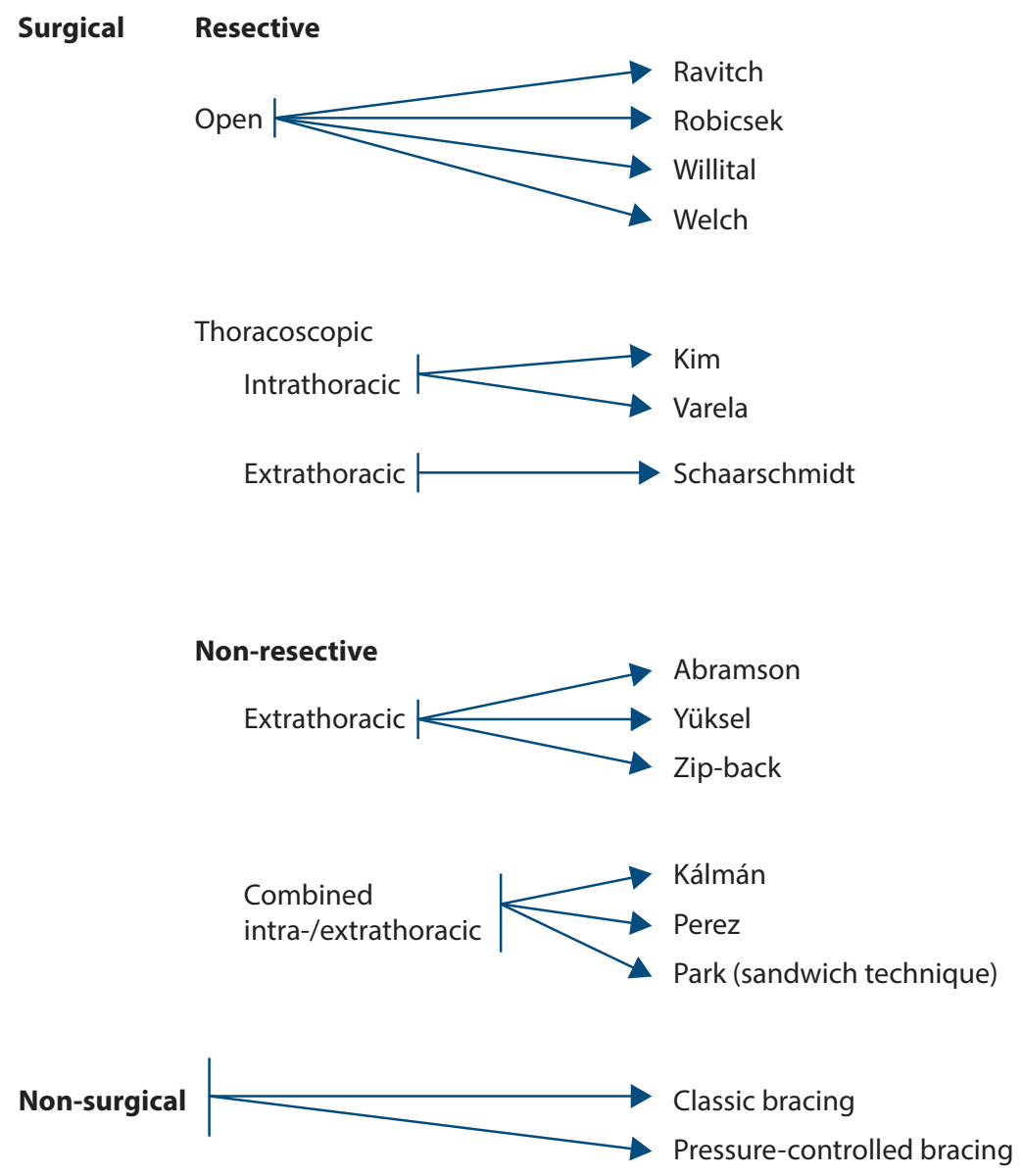

Fig. 5. Classification of treatments for pectus carinatum (adapted from Holcomb et al. ${ }^{[15]}$ ). ample resection of several cartilages, with perichondrium preservation and sternal osteotomies fixed with small bars that require subsequent removal. Disadvantages of this operation include significant blood loss, long operating time and considerable damage to soft tissues. ${ }^{[16]}$ Asphyxiating chondrodystrophy has been reported as a result of open resective surgeries done too early in childhood in pectus excavatum patients (though this is less likely in pectus carinatum cases). ${ }^{[17,18]}$ Far from being abandoned, these surgeries, or variations of them, are still the first choice in cases of very deformed, rigid, non-articulated sternums with associated malformations, or after other approaches have failed.

\section{Resective techniques}

Open resective techniques: The Ravitch, ${ }^{[12]}$ Robicsek, ${ }^{[19]}$ Willital $^{[21]}$ and Welch ${ }^{[20]}$ were the most commonly used open resective techniques prior to Nuss et al.'s ${ }^{[13]}$ first report of minimally invasive surgery for pectus excavatum.

Ravitch's ${ }^{[12]}$ first report of an open correction of a pectus carinatum deformity established a series of steps, including cartilage resection of the ribs, sternum osteotomies and fixation. Robicsek et al. ${ }^{[19]}$ reported an upper sternal osteotomy and resection of its lower angulated portion and the xiphoid process. Shamberger and Welch ${ }^{[20]}$ reported on their extensive experience using bilateral cartilage resection, even in cases of pectus carinatum, as well as various osteotomies, depending on the type of sternal deformity. Saxena and Willital ${ }^{[21]}$ reported extensive chondral and distal segments of ribs, detorsion of the sternum with retrosternal mobilisation and fixation with trans-sternal and lateral parasternal metal struts. It is now generally agreed that chondral resection must ensure preservation of the perichondrium to allow for cartilage regrowth (Fig. 6).

Minimally invasive resective techniques: Following the introduction of minimally invasive surgery, thoracoscopic options appeared. One of these was the Nuss procedure for pectus excavatum. Thoracoscopic resective correction is further classified as intra- or extrathoracic.

The Kim and Varela techniques are two examples of thoracoscopic resective intrathoracic surgeries for the correction of carinatum deformities. Kim and Idowu ${ }^{[22]}$ 
reported multiple short chondral and rib segmental resection with preservation of the anterior perichondrium from an intrathoracic aspect under thoracoscopic vision. Varela and Torre ${ }^{[23]}$ extended Kim's resection, and excised the affected cartilages completely using three ports.

Schaarschmidt et al. ${ }^{[24]}$ reported an extrathoracic resective thoracoscopic approach to pectus carinatum by means of sub-pectoral carbon dioxide dissection. Carbon dioxide insufflation was used to dissect the pectoral muscles from the entire anterior thoracic wall. Through a small incision of $2.9-4.7 \mathrm{~cm}$, and the port holes, wedge resections of the cartilages and osteotomies of the sternum were performed as necessary, with subsequent fixation with bars that were removed later.

\section{Non-resective techniques}

Non-resective techniques were the result of the fundamental conceptual change brought about by Nuss et al.' ${ }^{[13]}$ introduction of chest remodelling. The avoidance of resection implies thoracoscopy, with smaller lateral incisions resulting in better cosmesis, less blood loss and shorter operative time. Dystrophy of chondral rib segments is no longer a concern, since growth plates are unaffected. However, these techniques are more effective in flexible thoracic cages that are also amenable to non-operative bracing, so their use in pectus carinatum is gradually decreasing.

Non-resective modalities can be further sub-classified into extrathoracic and combined intra- and extrathoracic.

Non-resective extrathoracic: The first report on non-resective extrathoracic treatment of pectus carinatum, or 'reverse Nuss', was by Abramson. ${ }^{[25,26]}$ The technique consisted of the placement of a subcutaneous steel bar, introduced through thoracic lateral incisions, and stabilised with two lateral steel devices and steel wire at the incision site (Fig. 7). Modifications of this technique have been published, such as one by Yüksel et al. ${ }^{[27]}$ that uses newly designed implants, the aim of which is to reduce dislocation, one of the most relevant complications of the technique (Fig. 8). In 2018, Yüksel et al. ${ }^{[28]}$ reported his experience with 172 patients over 10 years, and four generations of chest bars, with excellent results in $93.8 \%$ of the cases.

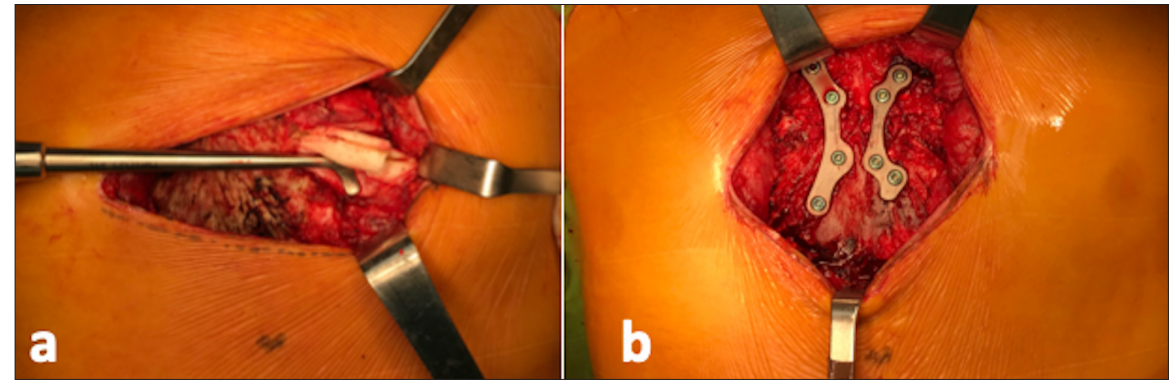

Fig. 6. Typical open resective surgery: (a) cartilage resection with preservation of perichondrium, and (b) sternal osteotomy with stabilisation by means of titanium plates and screws.

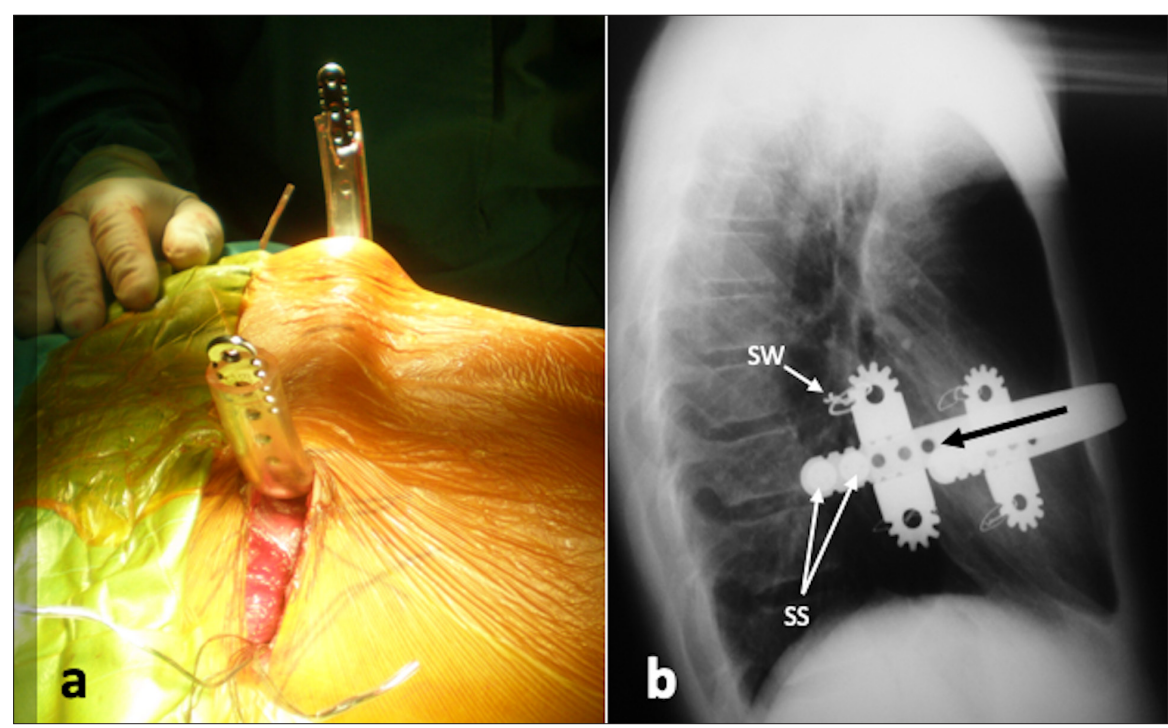

Fig. 7. Abramson technique or reverse Nuss, as modified by Martinez-Ferro et al.: (a) a subcutaneous bar is passed pre-sternally; (b) postoperative X-rays showing the bar in place. The stabilisers are fixed to the ribs by means of stainless steel wire (SW). The bar is pushed from front to back (black arrow) using the stabilisers as a guide. Specially designed screws prevent the bar from sliding back (SS).

Recently, Bellia-Munzon et al. ${ }^{[29]}$ have reported the zip-back technique. This approach avoids the use of lateral stabilisers, fixing the implant directly to the ribs by means of specially designed polymer zip-ties (Fig. 9).

In addition to avoiding resection of cartilage and sternal osteotomies, the advantages of non-resective extrathoracic techniques include smaller scars at the side of the chest and a complete reshaping of the chest wall, instead of the local correction of the deformity offered by open resective approaches. This complete remodelling of the chest includes the widening and flattening of the whole anterior chest, with consequent improvement of shoulder and spine posture (Fig. 10).

Non-resective combined intra-/ extrathoracic: Several authors, such as Kálmán, ${ }^{[30]}$ Pérez et al. ${ }^{[31]}$ and Park and Kim, ${ }^{[32]}$ have reported variations of nonresective combined intra-/extrathoracic surgeries. Kálmán ${ }^{[30]}$ used a modelled bar introduced into the thoracic cavity from the left aspect of the thorax, extruded into the subcutaneous tissue at the point of maximum protrusion of the sternum and reintroduced into the thorax parasternally to the right, fixed with absorbable sutures and meant to avoid the use of stabilisers. Pérez et al. ${ }^{[3]]}$ used a steel bar $2 \mathrm{~cm}$ longer on each side than the interareolar distance, and introduced it from the right side into the thorax, exited out of the pleural space and advanced it anteriorly to the sternum at the site of maximum protrusion and then reintroduced into the thorax, leaving the tip of the bar inside the pleural space. Finally, Park and Kim ${ }^{[32]}$ developed the carinatum or carinatum/excavatum complex. This operation requires two bars, an internal implant for excavatum correction and an external for carinatum, with excellent results. 'sandwich technique' for asymmetric pectus 

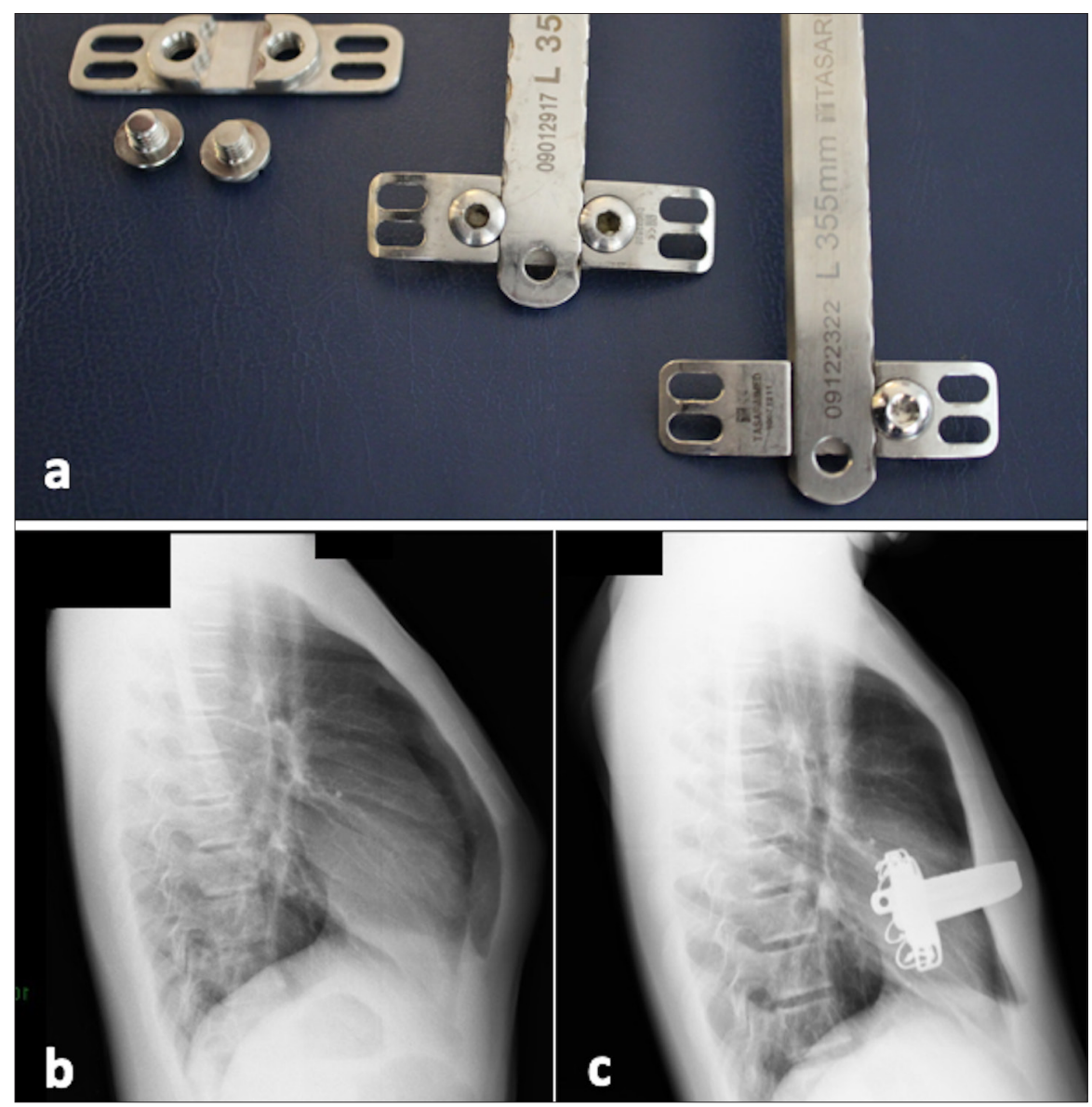

Fig. 8. Yüksel's minimally invasive technique for pectus carinatum: (a) modified extrathoracic implants with different original fixation mechanism; (b) preoperative X-rays; (c) postoperative X-rays.

\section{Non-surgical treatments}

Bracing therapy has gained popularity as a non-operative alternative that has proven to be as good as operative strategies to correct pectus carinatum in patients with flexible thoracic cages and high compliance. This is a good choice as the first line of treatment in almost all cases, and the only solution necessary in many cases with non-complex deformities, flexible thoracic cages and a high level of compliance. This last aspect is the major cause of failure of treatment and abandonment, so a multidisciplinary approach is recommended, with the participation of rehabilitation physicians and physical therapists. There is still a lack of consensus regarding the minimum number of hours patients should wear the brace, and whether bracing may play a role in adult patients. Non-surgical treatments may be classified as classic bracing or pressurecontrolled bracing.

The first reports on bracing for pectus carinatum were published by Jaubert de Beaujeu $^{[33]}$ and Bianchi ${ }^{[34]}$ in the 1960s. Haje et al.$^{[35-38]}$ reported the use of an orthosis referred to as the dynamic chest compressor, and later their extensive experience using the dynamic brace in mild to moderate cases. Since 2000, there have been many reports on

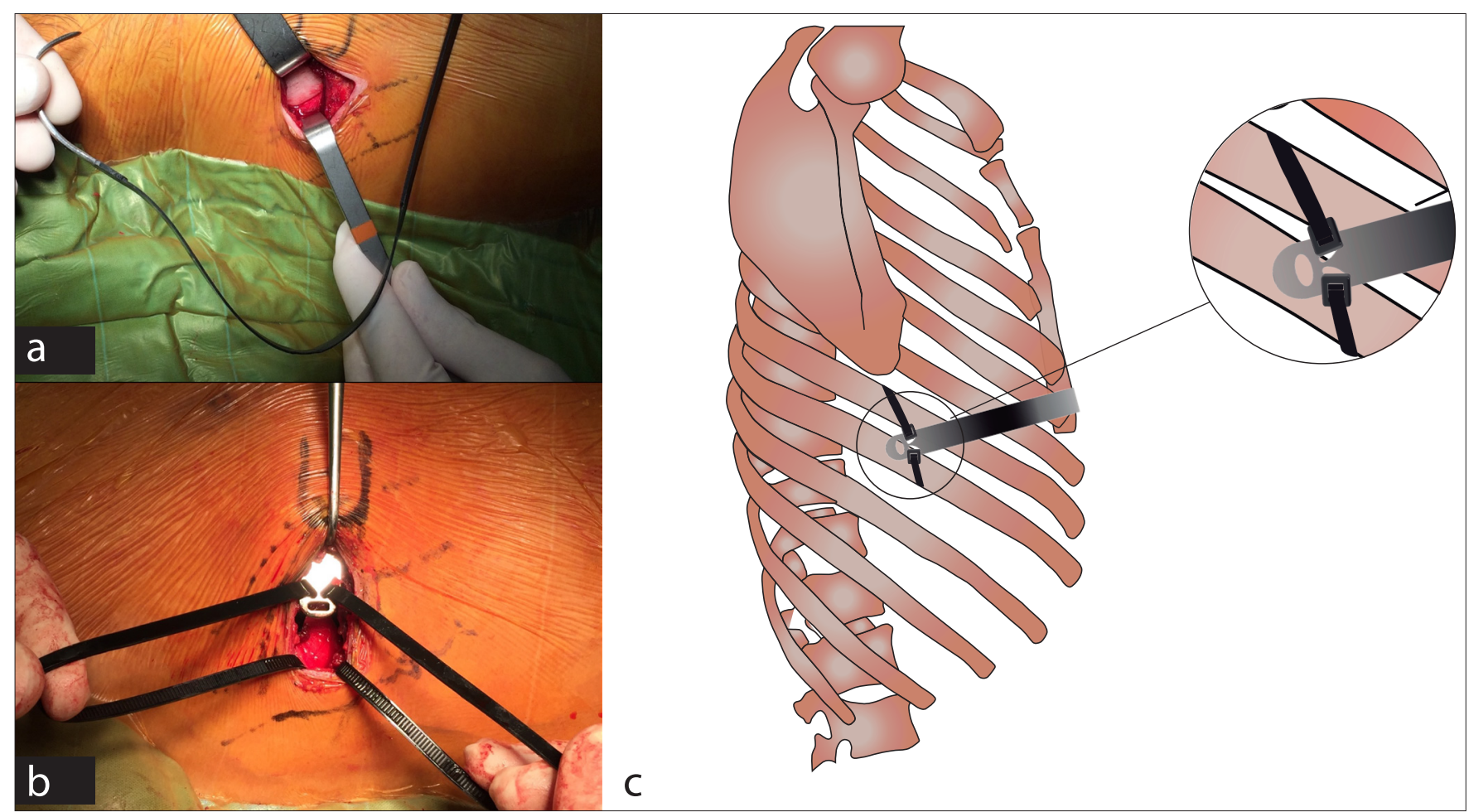

Fig. 9. Zip-back technique: the implant is fixed directly to the ribs with specially designed polymer zip-ties. (a) Zip-tie with blunt needle in the tip that will be passed around the dissected rib; (b) zip-ties passed through the ribs, and the implants' eyelets ready to be fixed; (c) details of the technique. 
the use of classic braces for the treatment of the carinatum deformity. ${ }^{[40-47]}$

In 2008, Martinez-Ferro et al. ${ }^{[6]}$ published an 8 -year review on the use of a specially designed dynamic compression system (the FMF Dynamic Compression System) (Fig. 11).

This system comprises multiple adjustable elements and a special device that monitors pressure. The concept of pressure of initial correction (PIC) was developed to describe the pressure necessary to completely correct the deformity, by means of measuring the rigidity of the thoracic cage. This permits the doctor to predict prognosis. Pressure of treatment (POT) was also developed to calculate the pressure needed at each adjustment when the patient sees the doctor again. Pounds per square inch (psi) is used as the unit of measure, and pressure under 2.5 psi was considered safe in order to avoid skin lesions. Subsequent authors have also reported their experience with the use of

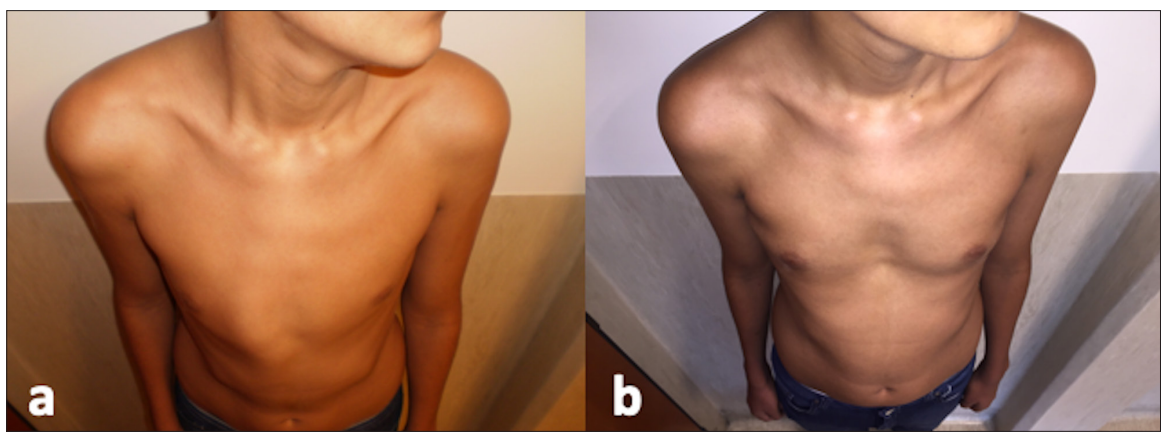

Fig. 10. Zip-back technique, before and after: complete reshaping of the thoracic cage is obtained. (a) Preoperative; and (b) 6 months postoperative, showing flattening and widening of the whole anterior chest wall.

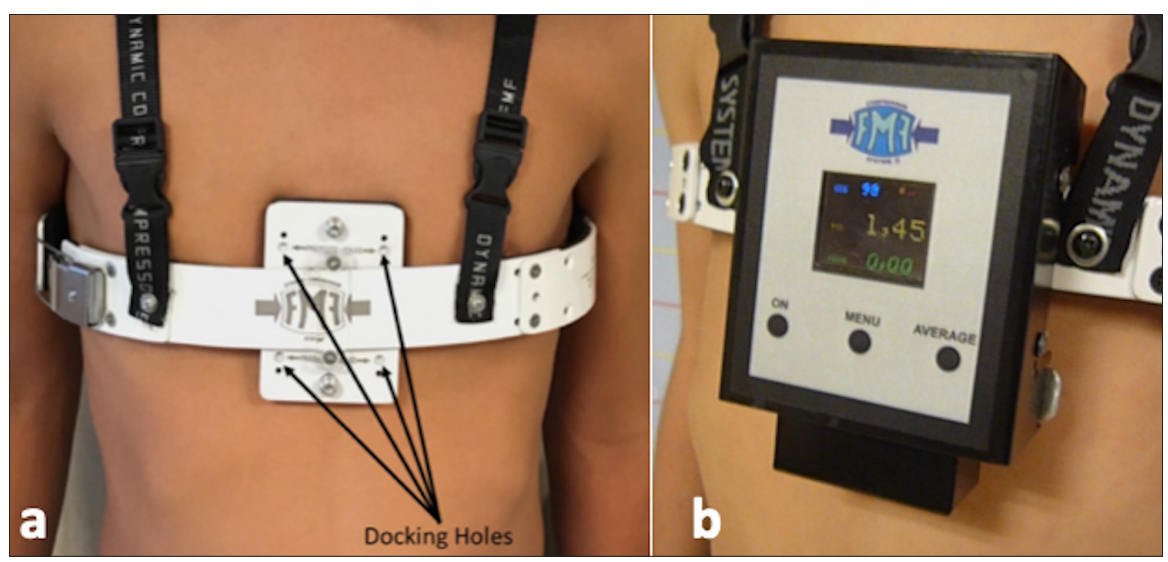

Fig. 11. Pressure-measuring devices allow protocolisation of follow-up and determination of cutoff values. (a) FMF Dynamic Compressor System in place. Docking holes permit measuring the pressure of treatment with a device. (b) Pressure-measuring device docked in place.
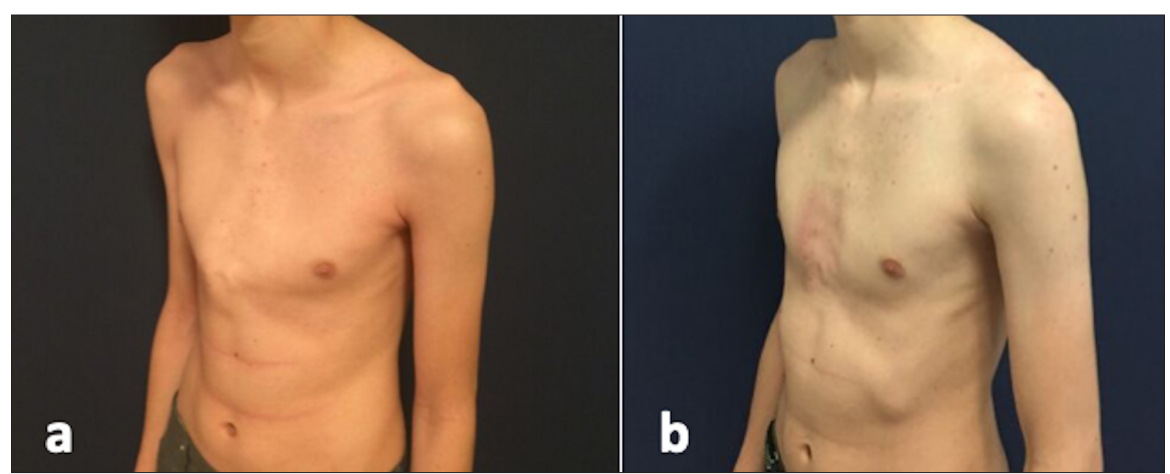

Fig. 12. Results obtained with dynamic compression of the chest wall, (a) prior to treatment and (b) after 6 months of treatment.

this device: Lopez et al. ${ }^{[48]}$ reported its use in patients with PIC as high as $14 \mathrm{psi}$, with good results in 61 of 68 cases in 17 months; and Cohee et al. ${ }^{[49]}$ created an algorithm designed to determine the chances of the condition being resolved with a non-operative approach. De Beer et al. ${ }^{[52]}$ validated the use of PIC to predict the duration of treatment, and Poola et al. ${ }^{[51]}$ found that a low PIC at the beginning of treatment was a good prognostic factor. In 2018, de Beer et al..$^{[50]}$ published a systematic review of the measured dynamic compression system. They found 14 studies published between 2008 and 2018, and selected 8 for further analysis. A total of 1185 patients were included, of whom $44 \%$ were still under treatment, $29 \%$ had completed treatment successfully, $6 \%$ had dropped out and $21 \%$ were lost to follow-up. Strategies are needed to decrease rates of abandonment by increasing compliance, which will probably improve results.

Overall, the results obtained with bracing are considered better than those obtained with surgical procedures (Fig. 12), making this the first treatment of choice for compliant patients with pectus carinatum.

\section{Conclusion}

We have described the history of the treatment of pectus carinatum, which has changed dramatically over the last 70 years, from the first descriptions of large incisions and wide resections, to minimal access strategies and, finally, to highly efficient non-operative solutions, in a trend towards minimising invasiveness. Today, with a wide variety of choices, treatment modalities are transitioning towards a tailor-made strategy for each patient.

\section{Acknowledgements. None.}

Author contributions. Equal contributions. Funding. None.

Conflicts of interest. None.

\footnotetext{
1. Fonkalsrud EW. Surgical correction of pectus carinatum: Lessons learned from 260 patients. J Pediatr Surg 2008;43(7):1235-1243. https://doi. org/10.1016/j.jpedsurg.2008.02.007

2. Cobben JM, Oostra RJ, van Dijk FS. Pectus excavatum and carinatum. Eur J Med Genet 2014;57(8):414-417. https://doi.org/10.1016/j.ejmg.2014.04.017

3. Chin EF. Surgery of funnel chest and congenital sternal prominence. Br J Surg 1957;44(186):360-376. https:// doi.org/10.1002/bjs.18004418607

4. Currarino G, Silverman FN. Premature obliteration of the sternal sutures and pigeon breast deformity. Radiology 1958;70(4):532-540. https://doi. org $/ 10.1148 / 70.4 .532$
} 
5. Fokin AA, Steuerwald NM, Ahrens WA, et al. Anatomical, histologic and genetic characteristics of congenital chest wall deformities. Semin Thorac Cardiovasc Surg 2009;21(1):44-57. https://doi.org/10.1053/j.semtcvs.2009.03.001

6. Martinez-Ferro M, Fraire C, Bernard S. Dynamic Compression System for the correction of pectus carinatum. Semin Pediatr Surg 2008;17(3):194-200. https://doi. org/10.1053/j.sempedsurg.2008.03.008

7. Robicsek F, Cook JW, Daugherty HK, et al. Pectus carinatum. J Thorac Cardiovasc Surg 1979;78:52-61.

8. Hebra A, Thomas PB, Tagge EP, et al. Pectus carinatum as a sequela of minimally invasive pectus excavatum repair. Pediatr Endosurg Innovat Techn 2002;6(1):41-44. https://doi.org/10.1089/10926410252832456

9. Swanson JW, Colombani PM. Reactive pectus carinatum in patients treated for pectus excavatum. J Pediatr Surg 2008;43(8):1468-1473. https://doi.org/10.1016/j. jpedsurg.2007.11.019

10. Szafer D, Taylor JS, Pei A, et al. A simplified method for three-dimensional optical imaging and measurement of patients with chest wall deformities. J Laparoendosc Adv Surg Tech A 2019;29(2):267-271. https://doi.org/10.1089/lap.2018.0191

11. Lain A, Garcia L, Gine C, et al. New methods for imaging evaluation of chest wall deformities. Front Pediatr 2017;4(5):257. https://doi.org/10.3389/fped.2017.00257

12. Ravitch MM. Unusual sternal deformity with cardiac symptoms: Operative correction. J Thorac Surg 1952;23:138-144.

13. Nuss D, Kelly RE Jr, Croitoru DP, Katz ME. A 10-year review of a minimally invasive technique for the correction of pectus excavatum. J Pediatr Surg 1998;33(4):545552. https://doi.org/10.1016/s0022-3468(98)90314-1

14. Haje SA, Raymundo JLP. Considerações sobre deformidades da parede torácica anterior e apresentação de tratamento conservador para as formas com componentes de protrusão. Rev Bras Ortop 1979;14(4):167-178.

15. Holcomb GW III, Murphy JP, Shawn D, Gatti JK. Holcomb and Ashcroft's Pediatric Surgery (7th edition). Edinburgh: Elsevier, 2019.

16. Mao YZ, Tang S, Li S. Comparison of the Nuss versus Ravitch procedure for pectus excavatum repair: An updated meta-analysis. J Pediatr Surg 2017;52(10):1545-1552. https://doi.org/10.1016/j.jpedsurg.2017.05.028

17. Martinez D, Juame J, Stein T, Pena A. The effect of costal cartilage resection on chest wall development. Pediatr Surg Int 1990;5(3):170-173. https://doi.org/10.1007/ bf00179655

18. Haller JA, Colombani PM, Humphries CT, et al. Chest wall constriction after too extensive and too early operations for pectus excavatum. Ann Thorac Surg 1996;61:16181625. https://doi.org/10.1016/0003-4975(96)00179-8

19. Robicsek F, Sanger PW, Taylor FH, et al. The surgical treatment of chondrosternal prominence (pectus carinatum). J Thorac Cardiovasc Surg 1963;45:691.

20. Shamberger RC, Welch KJ. Surgical correction of pectus carinatum. J Pediatr Surg 1987;22(1):48-53. https://doi.org/10.1016/s0022-3468(87)80014-3

21. Saxena AK, Willital GH. Surgical repair of pectus carinatum. Int Surg 1999;84(4):326-330.

22. Kim S, Idowu O. Minimally invasive thoracoscopic repair of unilateral pectus carinatum. J Pediatr Surg 2009;44(2):471-474. https://doi.org/10.1016/j.jpedsurg.2008.09.020

23. Varela $\mathrm{P}$, Torre M. Thoracoscopic cartilage resection with partial perichondrium preservation in unilateral pectus carinatum: Preliminary results. J Pediatr Surg 2011;46(1):263-266. https://doi.org/10.1016/j.jpedsurg.2010.08.010

24. Schaarschmidt K, Kolberg-Schwerdt A, Lempe-Sellin M, Schlesinger F. New endoscopic minimal access pectus carinatum repair using subpectoral carbon dioxide. Ann Thorac Surg 2006;81(3):1099-1103. https://doi.org/10.1016/j.athoracsur.2005.10.042

25. Abramson H. [A minimally invasive technique to repair pectus carinatum. Preliminary report]. Arch Bronconeumol 2005;41(6):349-351. https://doi.org/10.1016/s15792129(06)60235-8

26. Abramson H, D’Agostino J, Wuscovi S. A 5-year experience with a minimally invasive technique for pectus carinatum repair. J Pediatr Surg 2009;44(1):118-123. https://doi. org/10.1016/j.jpedsurg.2008.10.020

27. Yüksel M, Bostanci K, Evman S. Minimally invasive repair of pectus carinatum using a newly designed bar and stabiliser: A single-institution experience. Eur J Cardiothorac Surg 2011;40(2):339-342. https://doi.org/10.1016/j.ejcts.2010.11.047

28. Yüksel M, Lacin T, Ermerak NO, Sirzai EY, Sayan B. Minimally invasive repair of pectus carinatum. Ann Thorac Surg 2018;105(3):915-923. https://doi.org/10.1016/j. athoracsur.2017.10.003

29. Bellia-Munzon G, Martinez JL, Millan C, et al. Zip to the rib: Sternal pull-back (zipback): Innovative approach for pectus excavatum. IPEG 27nd Annual Congress for Endosurgery in Children. Seattle, USA. April 2018.
30. Kálmán A. Initial results with minimally invasive repair of pectus carinatum. J Thorac Cardiovasc Surg 2009;138(2):434-438. https://doi.org/10.1016/j.jtcvs.2008.12.032

31. Pérez D, Cano JR, Quevedo S, López L. New minimally invasive technique for correction of pectus carinatum. Eur J Cardiothorac Surg 2011;39(2):271-273. https:// doi.org/10.1016/j.ejcts.2010.05.024

32. Park HJ, Kim KS. The sandwich technique for repair of pectus carinatum and excavatum/carinatum complex. Ann Cardiothorac Surg 2016;5(5):434-439. https:// doi.org/10.21037/acs.2016.08.04

33. Jaubert de Beaujeu M. Thorax en carène. Lyon Chir 1964;60:440-443.

34. Bianchi C. Risultati a distanza 20 casi di 'cifosi sternale' tratti incruentemente. Fracastoro 1968;61:779-792.

35. Haje SA, Bowen JR. Preliminary results of orthotic treatment of pectus deformities in children and adolescents. J Pediatr Orthop 1992;12(6):795-800. https://doi. org/10.1097/01241398-199211000-00018

36. Haje SA, Bowen JR, Harcke HT, et al. Disorders in the sternum growth and pectus deformities: An experimental model and clinical correlation. Acta Orthop Bras 1998;6:67-75. https://doi.org/10.1007/s002470050602

37. Haje SA, Harcke HT, Bowen JR. Growth disturbance of the sternum and pectus deformities: Imaging studies and clinical correlation. Pediatr Radiol 1999;29(5):334-341.

38. Haje A, Haje DP, Silva Neto M, et al. Pectus deformities: Tomographic analysis and clinical correlation. Skeletal Radiol 2010;39(8):773-782. https://doi.org/10.1007/ s002470050602

39. Egan JC, DuBois JJ, Morphy M, Samples TL, Lindell B. Compressive orthotics in the treatment of asymmetric pectus carinatum: A preliminary report with an objective radiographic marker. J Pediatr Surg 2000;35(8):1183-1186. https://doi.org/10.1053/ jpsu.2000.8724

40. Banever GT, Konefal SH, Gettens K, Moriarty KP. Non-operative correction of pectus carinatum with orthotic bracing. J Laparoendosc Adv Surg Tech A 2006;16(2):164167. https://doi.org/10.1089/lap.2006.16.164

41. Frey AS, Garcia VF, Brown RL, et al. Non-operative management of pectus carinatum. J Pediatr Surg 2006;41(1):40-45. https://doi.org/10.1016/j.jpedsurg.2005.10.076

42. Kravarusic D, Dicken BJ, Dewar R, et al. The Calgary protocol for bracing of pectus carinatum: A preliminary report. J Pediatr Surg 2006;41(5):923-926. https://doi. org/10.1016/j.jpedsurg.2006.01.058

43. Jung J, Chung SH, Cho JK, Park SJ, Choi H, Lee S. Brace compression for treatment of pectus carinatum. Korean J Thorac Cardiovasc Surg 2012;45(6):396-400. https:// doi.org/10.5090/kitcs.2012.45.6.396

44. Loff S, Sauter H, Wirth T, Otte R. Highly efficient conservative treatment of pectus carinatum in compliant patients. Eur J Pediatr Surg 2015;25(5):421-424. https://doi. org/10.1055/s-0034-1384648

45. Wong KE, Gorton GE 3rd, Tashjian DB, Tirabassi MV, Moriarty KP. Evaluation of the treatment of pectus carinatum with compressive orthotic bracing using threedimensional body scans. J Pediatr Surg 2014;49(6):924-927. https://doi.org/10.1016/j. jpedsurg.2014.01.024

46. Lee SY, Lee SJ, Jeon CW, Lee CS, Lee KR. Effect of the compressive brace in pectus carinatum. Eur J Cardiothorac Surg 2008;34(1):146-149. https://doi.org/10.1016/j. ejcts.2008.04.012

47. Lee RT, Moorman S, Schneider M, Sigalet DL. Bracing is an effective therapy for pectus carinatum: Interim results. J Pediatr Surg 2013;48(1):184-190. https://doi. org/10.1016/j.jpedsurg.2012.10.037

48. Lopez M, Patoir A, Varlet F, et al. Preliminary study of efficacy of dynamic compression system in the correction of typical pectus carinatum. Eur J Cardiothorac Surg 2013;44(5):e316-319. https://doi.org/10.1093/ejcts/ezt425

49. Cohee AS, Lin JR, Frantz FW, Kelly Jr RE. Staged management of pectus carinatum. J Pediatr Surg 2013;48(2):315-320. https://doi.org/10.1016/j.jpedsurg.2012.11.008

50. De Beer SA, Gritter M, de Jong JR, van Heurn EL. The dynamic compression brace for pectus carinatum: Intermediate results in 286 patients. Ann Thorac Surg 2017;103(6):1742-1749. https://doi.org/10.1016/j.athoracsur.2016.12.019

51. Poola AS, Pierce AL, Orrick BA, et al. A single-centre experience with dynamic compression bracing for children with pectus carinatum. Eur J Pediatr Surg 2018;28(1):12-17. https://doi.org/10.1055/s-0037-1606845

52. De Beer SA, Blom YA, Lopez M, de Jong JR. Measured dynamic compression for pectus carinatum: A systematic review. Semin Pediatr Surg 2018;27(3):175-182. https://doi.org/10.1053/j.sempedsurg.2018.06.001

Accepted 13 August 2019 